\title{
Argumentação e autoria de adolescentes booktubers: interfaces entre a sala de aula e o ambiente virtual
}

\section{Valéria Fernandes Turci}

Mestranda do Programa de Pós-Graduação em Educação da Universidade de São Paulo (USP) valeria.f.turci@gmail.com

\section{Soraya Maria Romano Pacífico}

Docente da Universidade de São Paulo (USP), Brasil

smrpacifico@ffclrp.usp.br

Resumo: Ao nos atentarmos para o fato de que os gêneros digitais ganham cada vez mais destaque na comunicação e que muitos alunos acessam canais no Youtube para visualizar resenhas de Booktubers sobre livros, propusemo-nos a inserir no contexto escolar essa prática de letramento, com o objetivo de investigar se o discurso realizado em ambiente virtual indicia marcas de autoria e argumentação dos alunos ao recontar e indicar (ou não) a leitura de obras literárias, realizadas em sala de aula e para além dela. Para o desenvolvimento da pesquisa, nossa referência teórica é a Análise de Discurso fundada por Michel Pêcheux. Nosso corpus será composto por vídeos, elaborados por alunos do ensino fundamental de uma escola pública de Ribeirão Preto/SP. Os resultados de nossas análises demonstram que o discurso dos sujeitos-alunos aponta marcas de autoria e argumentação quando as condições de produção discursivas permitem aos interlocutores a disputa dos sentidos, não desprezam a opacidade da linguagem, tampouco que assumir uma posição ou outra, no discurso, não é um ato neutro, seja qual for o espaço discursivo.

Palavras-chave: Argumentação. Autoria. Discurso. Educação.

Abstract: Since digital genres are becoming more and more relevant in communication today, and many teenagers access Youtube channels to visualize booktubers' book reviews, we proposed to insert this literacy practice into the school context, in order to investigate if the discourses construed in a virtual environment show marks of authorship and argumentation of the students when retelling and recommending (or not) the reading of literary works, performed in classroom and beyond. Our theoretical reference for this research was the Discourse Analysis approach founded by Michel Pêcheux. Our corpus is composed of videos that were elaborated by Elementary School students from a public school in Ribeirão Preto, São Paulo. The results of our analysis demonstrated that the discourses of the student-subjects presented signs of authorship and argumentation when the conditions of discursive production allowed interlocutors to dispute the senses, did not neglect the opacity of language, and that taking one or the other position in discourse is not a neutral act, whatever the discursive space.

Keywords: Argumentation. Authorship. Discourse. Education. 


\section{Introdução}

A velocidade da internet, o desenvolvimento e a multiplicação de sites de rede sociais instauraram espaços discursivos em que os sentidos emergem de forma globalizada. Ao nos atentarmos para o fato de que os gêneros digitais ganham cada vez mais destaque na comunicação e que muitos alunos acessam canais no Youtube para visualizar comentários de Booktubers ${ }^{1}$ sobre livros, propusemo-nos a inserir no contexto escolar essa prática de letramento, com o objetivo de investigar se o discurso realizado no espaço virtual indicia marcas de autoria e argumentação dos alunos ao recontar e indicar (ou não) a leitura de obras literárias, realizadas em sala de aula e para além dela.

Para isso, criamos um canal de vídeos no Youtube com a finalidade de hospedar os vídeos com as resenhas de livros elaboradas pelos alunos, canal que, no decorrer da pesquisa, tornou-se um site. Nesse site, intitulado Literatuber $^{2}$, criado especificamente para a pesquisa, é possível acessar os vídeos dos alunos de forma unificada e simplificada, sem a interferência de propagandas, uma vez que ao selecionar o vídeo a ser assistido, o internauta será direcionado ao canal no Youtube. Além desses vídeos com resenhas, também faz parte do corpus de nossa pesquisa a produção de vídeos que versam sobre o papel da mulher na sociedade contemporânea, os quais foram elaborados a partir de discussões e debates realizados em sala de aula, após a leitura da obra Capitães da areia, de Jorge Amado.

Neste trabalho, trazemos quatro recortes de um corpus maior, que integra a pesquisa "Da ponta do lápis às redes sociais: argumentação e autoria em discurso", realizada durante o ano de 2018, na Faculdade de Filosofia Ciências e Letras da Universidade de São Paulo - FFCLRP/USP. Para nortear nossos estudos, consideramos os pressupostos teóricos da Análise do Discurso de 'linha' francesa, cujo principal expoente é Michel Pêcheux, bem como os estudos de Bauman (2001), Dias (2018), Orlandi (1999, 2012), Pacífico (2012, 2016), entre outros.

\footnotetext{
${ }^{1}$ Nomeação dada aos internautas que têm um canal de resenhas de livros no Youtube, onde fazem comentários sobre as obras lidas e indicam (ou não) a sua leitura.

${ }^{2}$ Disponível em: http://literatuber.com.br Acesso em: 09 ago. 2019
} 


\section{Questões metodológicas}

A presente pesquisa foi realizada em uma escola da rede municipal de ensino do município de Ribeirão Preto, localizada em um bairro da zona leste da cidade, onde os moradores são, predominantemente, de classe médiabaixa. A escola atendia no ano da realização da pesquisa a 718 estudantes, sendo 313 matriculados nos anos iniciais e 405 nos anos finais do ensino fundamental. A instituição está em funcionamento há mais de 50 anos e sua localização centralizada faz com que muitas famílias de bairros da periferia a procurem, o que gera uma grande lista de espera por vagas. Dos 718 estudantes que frequentam a escola, cerca de 500 deles não moravam no bairro, sendo oriundos de bairros adjacentes. A escola possui uma sala de informática, que conta com onze computadores e um monitor de informática para assessorar professores e alunos. Cada sala de aula é composta por 35 alunos, as aulas do $9^{\circ} \mathrm{A}$ e $\mathrm{B}$ ocorrem no período da manhã, e a prioridade para a escolha deste período é dos alunos que residem no bairro. No período da tarde, ocorrem as aulas do $9^{\circ}$ ano $\mathrm{C}$, turma composta, em sua maioria, por alunos de bairros adjacentes e por alunos de outras cidades, que jogam futebol em um clube próximo. Todos os alunos possuem smartphones, o que foi um facilitador para o desenvolvimento de nossa pesquisa, uma vez que o laboratório de informática da escola contava, no momento da realização das atividades, com apenas dois computadores em funcionamento. Diante disso, alguns vídeos foram elaborados na escola com o próprio celular dos alunos e com o celular do professor-pesquisador. Foi montado um local específico na sala de informática para que os alunos pudessem fazer a gravação com a ajuda do monitor de informática, que também os auxiliou na edição dos vídeos. Alguns alunos optaram por elaborar e editar o vídeo em casa, edição realizada com a ajuda de aplicativos como Movie maker, FilmoraGo, Kinemaster etc.

A escolha por essa instituição escolar deu-se em função de a pesquisadora ser docente na escola há nove anos, o que foi um facilitador para a autorização da realização da pesquisa pela direção da unidade escolar e também pela Secretaria Municipal da Educação. Outro facilitador foi a possibilidade de desenvolver os trabalhos com as três salas de $9^{\circ}$ ano, envolvendo, desse modo, um número maior de alunos. Somado a isso, no processo de coleta de dados, o fato de ocuparmos as posições discursivas de 
pesquisador e de docente da escola também contribuiu para nossa investigação, uma vez que pudemos ter amplo acesso às condições de produção dos trabalhos, elemento importante para as análises discursivas.

\section{Um percurso pela teoria discursiva, pela autoria e argumentação no espaço} escolar

Os sujeitos da pesquisa, jovens alunos, estudantes dos anos finais do ensino fundamental, subjetivam-se ao discursivizarem nas redes sociais, em uma prática discursiva que não está dissociada da assunção da autoria e indicia traços da singularidade do autor. Devemos considerar que eles nasceram e cresceram em uma sociedade digital que, conforme Dias (2018), vem produzindo transformações na discursividade do mundo, nas relações históricas, sociais e ideológicas, na constituição dos sujeitos e dos sentidos, na forma dos relacionamentos pessoais e na mobilidade, razão pela qual os estudos sobre o digital têm se configurado como um campo de questões imprescindíveis ao fazer científico.

O sociólogo e filósofo polonês Zygmunt Bauman, na obra Modernidade Líquida (2001), adota o termo 'líquido' como metáfora para ilustrar as mudanças nas formas de vida moderna, que se assemelham ao termo pela fluidez, e reforçam o estado temporário das relações sociais no mundo globalizado. De acordo com o autor, o surgimento das novas tecnologias trouxe incertezas quanto à capacidade de o ser humano adequar-se à liquidez dos novos padrões sociais, que mudam constantemente.

Nesse panorama, e compreendendo a linguagem como forma de interação e de constituição do sujeito, acreditamos que esse vínculo com o ambiente virtual também influencia essa constituição. Quando nos filiamos à Análise de Discurso, não estamos nos referindo ao sujeito gramatical ou empírico, tal como considera a Psicologia. Em uma perspectiva discursiva, o que há são posições sujeito, ou seja, lugares sociais, e é a partir desses "lugares" que o sujeito produz o seu discurso. (PACífICO, 2012)

Ao analisar postagens nas redes sociais, Dias (2018) denomina esses usuários de sujeito de dados, visto que todas as informações compartilhadas na rede são de interesse para as grandes corporações, como o Google, a Microsoft e o Facebook. Tais dados, conforme a autora, são considerados 
"pérolas que polidas como serviços e produtos personalizados retornam de maneira muito lucrativa para as grandes empresas" (DIAS, 2018, p. 156).

Essa visão vai ao encontro do pensamento de Bauman (2001), ao considerar que, na contemporaneidade, os sujeitos vivem uma certa insatisfação constante, que pode estar relacionada à existência de uma infinita quantidade de possibilidades e oportunidades a serem exploradas, o que acaba gerando neles sentimentos de ansiedade devido à necessidade de fazer escolhas e, consequentemente, descartar opções. O autor destaca dois conceitos básicos em torno dos quais as narrativas da condição humana tendem a se desenvolver: o primeiro consiste na substituição da ideia de coletividade e solidariedade pela ideia de individualidade; e o segundo, na transformação do cidadão em consumidor.

Como já dissemos, ao abordarmos a constituição do sujeito contemporâneo, há que se considerar a sua relação com a tecnologia desde o seu nascimento, visto que a relação que os jovens mantêm com seus smartphones, com as redes sociais e com diversos recursos tecnológicos tem consequências no modo como se constituem como sujeitos. Para Dias (2018, p. 56), “todos esses processos maquinímicos portáteis e miniaturizados são parte dos modos de individuação do sujeito, pelo discurso da tecnologia, da 'era tecnológica', da 'era digital”', sendo por meio dessa individuação que ele se identifica, inscrevendo-se em determinadas formações discursivas.

Toda formação discursiva deriva de condições de produção específicas, inscritas numa relação de classes no interior de um aparelho ideológico e “determinam o que pode e deve ser dito [...], a partir de uma posição dada numa conjuntura" (PÊCHEUX, 2010 [1975], p. 164).

Nessas circunstâncias, analisar o discurso implica interpretar a linguagem conforme as suas condições de produção, em determinado contexto histórico e considerando o lugar de quem fala, já que a ideologia se materializa na língua. Conforme Pêcheux (2010 [1975]), a materialidade é o que permite observar a relação do real com o imaginário, ou seja, com a ideologia que funciona por meio do inconsciente.

Ao utilizarmos a linguagem para debatermos questões polêmicas, o que marca a posição divergente de grupos antagônicos é a ideologia, já que todo sujeito se posiciona a partir de sua formação ideológica. Para Pêcheux (2010 
[1975], p. 164) “a ideologia interpela os indivíduos em sujeitos”, e é assim que a língua faz sentido.

Portanto, o analista do discurso não concebe a existência da relação entre o pensamento/linguagem e o mundo, tal como concebida pela Psicologia, pois esta desconsidera os efeitos da ideologia e trabalha com a ilusão de transparência da linguagem. Conforme Orlandi (1996, p. 65), "a interpretação é sempre regida por condições de produção específicas que, no entanto, aparecem como universais e eternas. Disso resulta a impressão do sentido único e verdadeiro".

No entanto, as imagens construídas histórica e ideologicamente nas escolas sobre o ensino de língua nos remetem à estrutura e à padronização da língua, bem como à adoção de um único sentido, dado pelo autor do livro didático e geralmente reverberado pela voz do professor. Desse modo, a escola naturaliza o silenciamento das vozes dos alunos sem que esse processo de silenciamento seja percebido, pois ele acontece como se fosse natural, efeito este produzido pela ideologia.

Consideramos que argumentar é condição primordial para que o aluno participe de forma atuante na sociedade. No entanto, nossa experiência docente nos permite afirmar que a escola nem sempre dá condições para o aluno ter acesso ao arquivo, prática que se concretiza por meio da leitura e tampouco permite a instauração do discurso polêmico33 (ORLANDI, 2016).

É possível constatar também que as práticas discursivas argumentativas no contexto escolar começam a ser desenvolvidas efetivamente a partir do $9^{\circ}$ ano, por meio do gênero dissertação, um tipo de texto que costuma ser exigido em exames de seleção para vestibulares, vestibulinhos e demais concursos. Ao analisarmos as seis coleções aprovadas pelo PNLD para o período de 2017-2019, entre as seis, apenas uma delas inclui o trabalho efetivo com práticas discursivas argumentativas a partir do volume do sexto ano.

Aliado a isso, é comum o livro didático trazer recortes de textos descontextualizados e desatualizados, o que interdita o acesso do aluno a diferentes pontos de vista sobre determinado assunto e afeta as condições de produção dos sentidos. Partindo do princípio de que o livro, não raro, é o

\footnotetext{
${ }^{3}$ Conforme Orlandi (2011) o discurso polêmico apresenta um equilíbrio tenso entre a paráfrase e a polissemia e seu objeto é alvo de disputa entre os interlocutores.
} 
principal instrumento linguístico usado pelo docente nas escolas de todo país, é possível considerar que a maioria dos alunos concluem o ensino fundamental sem exercer o direito à argumentação no contexto escolar, o que trará implicações para além da escola, uma vez que não estão sendo preparados para participar discursivamente da sociedade, cujas práticas discursivas cotidianas sustentam-se (ou deveriam sustentar-se) na argumentação.

Do mesmo modo que Cândido (2004) defende a literatura como direito humano, defendemos que a argumentação também deve ser entendida assim, como um direito humano, devendo ser "legitimada na instituição escolar para que o sujeito, exercendo essa prática discursiva, sinta-se no direito de tomar a palavra, de mergulhar no fio discursivo e posicionar-se acerca dos sentidos colocados em circulação, na sociedade." (PACífICO, 2016, p.192)

É importante destacar que, neste trabalho, não estamos nos referindo à argumentação como possibilidade de persuasão, em que um orador específico deseja convencer seu interlocutor por meio de um debate, no qual há um vencedor. Conforme Piris (2016),

[...] uma análise discursiva da argumentação fundamentada na tese não idealista da linguagem não assume as perspectivas de estudo que tratam a argumentação como um jogo de estratégias arquitetadas por um orador plenamente consciente dos usos que ele faz dos recursos da linguagem para persuadir seu ouvinte. (PIRIS, 2016, p.105).

Desse modo, compreendemos a argumentação como dimensão de uma prática discursiva na qual ocorre a disputa dos sentidos. Considerando que todo sujeito discursa a partir de uma posição-sujeito, ao produzir um discurso, ele projeta uma imagem do outro sobre si, de si mesmo ao outro e uma imagem de si sobre si mesmo. Esse jogo de formações imaginárias faz parte da estratégia discursiva, pois regula a possibilidade de respostas e dirige a argumentação, o que Orlandi (1999) chama de mecanismo de antecipação:

Segundo o mecanismo da antecipação, todo o sujeito tem a capacidade de experimentar, ou melhor, de colocar-se no lugar em que o seu interlocutor "ouve" suas palavras. Ele antecipa-se assim a seu interlocutor quanto ao sentido que suas palavras produzem. Esse mecanismo regula a argumentação, de tal forma que o sujeito dirá de um modo, ou de outro, segundo o efeito que pensa produzir em seu ouvinte. (ORLANDI, 1999, p.37). 
Considerando que as relações na sociedade são determinadas histórica e ideologicamente, o sujeito identifica-se (ou não) com seu ouvinte, antecipa-se a ele e toma sua posição perante a formação discursiva que o domina, a qual é determinada pela ideologia.

Nessa perspectiva, em uma prática docente autoritária, em que apenas o professor toma a palavra, sem permitir o debate e a troca de ideias, prática não rara nas escolas, as vozes dos alunos são silenciadas, impossibilitando, dessa forma, a construção de novos sentidos, a argumentação e a assunção da autoria.

Cabe ressaltar que não estamos nos referindo ao termo autoria na perspectiva de Foucault (2001), no que se refere à produção de um artigo ou obra literária, em que o nome do autor se constitui como legitimidade jurídica de um texto a ele associado, ou então, de critérios discursivos que associam a obra a seu nome.

Dialogando com outros estudiosos acerca do conceito de autoria, consideramos relevantes as colocações de Possenti (2009), que considera autoria como "dar voz a outros enunciadores, manter distância em relação ao próprio texto, evitar a mesmice, pelo menos" (p. 110). E acrescenta que a escola deveria propor estratégias de escrita com o objetivo de que escrever seja algo mais que acertar ou não a normatividade da língua.

Ao discutir o tema da escrita e da autoria, Rodrigues (2011) entende que a atividade de escrita nas instituições escolares está atravessada por determinações não apenas socioculturais, mas também históricas, econômicas e políticas, cujos efeitos ainda predominam nas escolas.

Só ultrapassando os limites reducionistas das abordagens centradas na estrutura do sistema linguístico é que a leitura e a escrita são capazes de contribuir para formar cidadãos ativos e conscientes de seu papel social, cidadãos que se compreendem, se posicionam diante da vida e do outro e, por isso, constroem memórias, registram histórias, reescrevem a existência, tornam-se protagonistas. Protagonismo que vem com a "publicização"4 do escrito, com a responsabilidade de quem escreve, com o reconhecimento do outro: condições para a construção do sujeito-autor. (RODRIGUES, 2011, p.17-18, grifos da autora)

\footnotetext{
${ }^{4}$ De acordo com Rodrigues (2011, p. 18), o termo refere-se não somente à impressão de textos, mas a qualquer processo de tornar público o escrito.
} 
Essas considerações são relevantes, pois nos remetem ao que, muitas vezes, observamos nas instituições escolares: o ato de escrever constitui-se de forma reducionista, sem a constituição prévia de um arquivo sobre o tema solicitado e, não raro, sem finalidade social, restringindo-se somente à análise linguística da produção elaborada pelos alunos.

Pfeiffer (2002) compreende que tornar-se autor não significa necessariamente ser original, mas abrir espaços de interpretação, de forma que o aluno sinta-se autorizado a dizer, "a ter o direito à produção de sentidos na linguagem, ser sujeito da linguagem”, sendo necessário, portanto, que seja garantida ao aluno essa oportunidade.

Ao discorrer sobre a função-autor, Orlandi (2016) propõe uma distinção entre a repetição empírica - exercício mnemônico que não produz sentidos; repetição formal como técnica de produção de frases e exercícios; e repetição histórica, que inscreve o discurso enquanto memória constitutiva. Dessa forma, “a inscrição do dizer no repetível histórico (interdiscurso) é que traz para a questão do autor a relação com a interpretação, pois o sentido que não se historiciza é ininteligível, ininterpretável, incompreensível. (1996, p. 70).

Nesse sentido, consideramos que, para argumentar, é necessário que a autoria se instale, o que somente ocorre por meio do protagonismo, do posicionamento diante da vida e do outro, sendo necessário, dessa forma, direcionar nossos olhares para os saberes que circulam na escola, para o ensino que nela se pratica e para os sujeitos que nela (se) significam, proporcionando papel de destaque ao trabalho com a argumentação e a autoria.

\section{Gestos argumentativos e indícios de autoria}

Compreendendo que, na Análise de Discurso, a teoria e a metodologia são processos indissociáveis, ao analista cabe investigar cada gesto de interpretação em sua materialidade, no momento em que o sentido faz sentido. Assim, devemos considerar os efeitos de sentido dos elementos que derivam da forma de sociedade em que vivemos, desde as relações sociais e o modo de viver na contemporaneidade até suas instituições, dentre elas a escola, com seu processo histórico permeado por relações de poder. Conforme já explicitamos, os sujeitos-alunos de nossa pesquisa produziram 
vídeos em ambiente real e virtual e debates em sala de aula. Para este trabalho, selecionamos quatro recortes e iniciaremos nossas análises pelas resenhas elaboradas para o canal Literatuber. O recorte 1 traz a resenha do livro Sob a Luz dos Seus Olhos, da autora Chris Melo; na sequência, trazemos o recorte 2 com a resenha do livro Percy Jackson e o Mar de Monstros, do autor Rick Riordan.

Recorte 1:

Oiê, tudo bem? Então, o trabalho que eu vou fazer é sobre o livro Sob a Luz dos Teus Olhos, da Chris Melo. A Chris Melo, ela já lançou cinco livros, e um deles "conhecidos" é Enquanto a Chuva Caía. Então, o livro conta sobre a história de uma menina, chamada Elisa, que quando ela decide enfrentar a vida adulta, e ir prum intercâmbio na Inglaterra. E lá ela acaba conhecendo um garoto chamado Paul, e eles acabam se apaixonando. E nessa história de romance e amor, acaba tendo um pouco de ação e suspense. É... esse livro é um livro indicado mais pra jovens, ele é um romance contemporâneo. Eu gostei muito desse livro, por esse livro retratar bastante uma história de amor e com muitos detalhes. Todos os capítulos dele, ele tem uma música, e eu achei isso muito interessante. Que nem aqui, no primeiro capítulo, é uma música dos Beatles [...]. Então, assim, todo capítulo, se você quiser ler, escutando uma música, você consegue. Eu achei isso muito interessante. Esse livro, realmente, eu escolhi ele porque ele despertou muitas emoções em mim. É, eu li esse livro com um papel, realmente com um papel do lado, porque eu chorei muito nesse livro. Ele despertou várias emoções boas e ruins, ele foi, ele me despertou raiva, tristeza, felicidade, mas eu gostei muito desse livro. Por isso que eu escolhi ele pra falar e realmente, assim, muitas pessoas podem não gostar dele, por conta dele ser muito, muito romântico, que ele é um romance contemporâneo. E por conta dele ser muito romântico, muito às vezes, ele acaba sendo romântico até demais, até ser meloso. Mas aí vai de pessoa pra pessoa. Eu, particularmente, gostei muito desse livro, e eu recomendo pra todo mundo esse livro. E é isso, gente, muito obrigada, tchau.

\section{Recorte 2:}

Eu sou o Laerte e hoje eu vim apresentar pra vocês o meu livro, Percy Jackson e o Mar de Monstros. O livro faz parte da coleção Percy Jackson e os Olimpianos, e eu gostei muito desse livro porque ele foi um dos livros que me colocou no mundo da leitura. Essa foi a primeira coleção que eu li "completo" e foi por ela que eu me apaixonei assim pelos livros. E eu recomendo muito esse livro porque foi um dos que realmente me marcou muito. E tipo, o final dele é muito surpreendente, porque, como é uma coleção, tem o primeiro, esse é o segundo, tem o terceiro e o quarto. Então, tipo assim, o final dele é o começo do terceiro, então é "muito" bom, 'cês vão querer ler o próximo, e o próximo, até terminar.

Na proposta de produção da resenha para o site Literatuber, a escolha do livro foi realizada pelos alunos; desse modo, a leitura não era uma atividade escolar realizada para elaborar uma avaliação da leitura ou o preenchimento 
de uma ficha de leitura, prática comumente observada nas escolas. Por meio dos recortes acima e dos demais vídeos que estão no site, é possível constatar o interesse pelos temas escolhidos, os quais podem ser considerados tão velhos e, ao mesmo tempo, tão atuais, como o preconceito racial, a mitologia greco-romana, o romantismo e o amor, que é universal e atemporal. Observamos que o sujeito-aluno do recorte 1 tem acesso a uma formação discursiva que circula muito na contemporaneidade, segundo a qual tudo que é muito romântico está fora de moda, é cansativo, traços característicos da sociedade contemporânea, em que os relacionamentos são efêmeros. Com base nesses sentidos, o sujeito-aluno argumenta e antecipa que pode ser contra-argumentado, "eu gostei, mas muita gente pode achar muito meloso e não gostar".

Destacamos, também, o uso do verbo gostar na primeira pessoa do singular em "eu gostei muito desse livro, por esse livro retratar bastante uma história de amor e com muitos detalhes". Para sustentar seu ponto de vista, o sujeito-aluno abre as páginas do livro e mostra ao interlocutor os trechos de músicas que o livro traz, o que indicia o funcionamento da argumentação com base em uma formação discursiva que relaciona música, no exemplo dado, dos Beatles, a romantismo e beleza. O sujeito-aluno usa uma voz de autoridade, Beatles, para defender sua argumentação a favor do romantismo. Ainda na defesa de seu ponto de vista, o sujeito complementa o fio argumentativo com o advérbio "realmente", como se lê em "Esse livro, 'realmente', eu escolhi ele porque despertou muitas emoções em mim [...]", uso linguístico que cria o efeito de sentido de que o sujeito não diz por dizer, mas sim, porque, na verdade, na realidade, ele sentiu emoção ao ler o livro; e finaliza sua resenha recomendando a leitura, ressaltando, com o uso de "particularmente" que esse é seu ponto de vista sobre o livro, como se lê em "Eu, 'particularmente', gostei muito desse livro, e eu recomendo pra todo mundo esse livro". Essa formulação sugere-nos uma abertura para que o interlocutor possa exercer seu próprio gesto de interpretação, ou seja, pode ou não concordar com a avaliação do sujeito-aluno sobre o livro indicado, abertura essa que a escola, muitas vezes, nega a seus alunos. Temos um sujeito que se autoriza a assumir um ponto de vista sobre o livro comentado e autoriza, do mesmo modo, seu interlocutor a gostar ou não do livro indicado. 
Em referência ao recorte 2, o sujeito-aluno apresenta seu ponto de vista argumentando que "o livro foi um dos que me colocou no mundo da leitura, foi a primeira coleção que li ‘completo' e foi por ela que me apaixonei pelos livros”. O argumento em defesa da coleção é construído com o uso do adjetivo "surpreendente", uso linguístico que pode estar filiado à formação imaginária segundo a qual um livro, para ser bom, deve ter um final surpreendente, que não seja previsível, que instigue o leitor.

Cabe destacar que, na atualidade, há coleções elaboradas especificamente para o público adolescente, as quais têm despertado nos sujeitos-contemporâneos o prazer da fruição da leitura, como podemos comprovar com a formulação "Foi por ela que me apaixonei pelos livros", fato que corrobora a visão já apresentada por nós sobre o trabalho com a leitura nas instituições escolares, que, geralmente, restringe-se a uma atividade escolar e não leva o leitor à fruição e ao deleite, tampouco cria oportunidades de o sujeito identificar-se com a leitura, de modo que reconheça a literatura como arte. Como já dissemos, nossa prática docente também nos mostra que é frequente nas escolas públicas e particulares o trabalho com a leitura de forma reducionista, onde o aluno lê um livro por bimestre ou trimestre, geralmente por obrigação e, na sequência, faz uma avaliação para atribuição de nota; quando não, outra proposta comumente solicitada aos alunos é a leitura de livros com o objetivo de preencher uma ficha de leitura e, assim, ter uma nota atribuída. Nossa visão é corroborada por Rodrigues (2011), que aborda as dificuldades da escola no trabalho com práticas de escrita e autoria e a necessidade de integrá-las ao cotidiano escolar:

As práticas discursivas precisam integrar-se ao cotidiano escolar e ao fazer pedagógico dos professores - em especial os de português - a fim de colaborarem no processo de formação de autores capazes de criar sentidos e recriar sensações, materializando pensamentos, expondo-se aos olhares de julgamentos alheios, hábeis em usar as palavras, seja para estar no mundo, seja para transformá-lo, uma vez que se posicionam como agentes políticos, sociais e culturais historicamente situados. (MÉSZÁROS, 2005, apud RODRIGUES, 2011, p. 42).

Por meio dos recortes apresentados, constatamos, também, o papel relevante que a literatura desempenha na vida dos sujeitos-alunos e pode ser um meio de promover práticas argumentativas no contexto escolar, como podemos observar com as seguintes formulações: "gostei muito desse livro, e 
eu recomendo pra ‘todo' mundo”; “foi a primeira coleção que eu li por completo e foi por ela que eu me apaixonei assim pelos livros"; "eu recomendo muito esse livro porque foi um dos que realmente me marcou muito" ou "é muito bom, "cês vão querer ler o próximo, e o próximo, até terminar".

Destacamos as marcas linguísticas, em negrito, porque, a nosso ver, elas apontam para a produção de sentidos de sujeitos que mantêm (no contexto escolar ou no virtual) interlocução com o outro, interlocução fundamental para a prática da argumentação. Segundo Mosca (2004), a argumentatividade faz parte de toda atividade discursiva, pois argumentar pressupõe considerar o outro, considerar a interação e a reação do sujeito diante de propostas e possibilidades que the são apresentadas. Implica, ainda, a possibilidade de discussão dos interlocutores frente ao objeto discursivo. "Na verdade, o envolvimento não é unilateral, tendo-se uma verdadeira arena em que os interesses se entrechocam, quando o clima é de negociação, em que prevalece o anseio de influência e de poder". (MOSCA, 2004, p. 17).

Dessa forma, isso reforça a importância das condições de produção do trabalho com a leitura na escola, de forma que ela desperte prazer, possibilidades de construção de sentidos em relação ao outro, autorizando, assim, os sujeitos-alunos a dizerem e a ocuparem a posição discursiva de sujeito que pode argumentar e ser autor do seu dizer.

Na sequência, trazemos recortes que fazem parte de vídeos produzidos pelos sujeitos-alunos de nossa pesquisa a partir do tema: O papel da mulher na sociedade contemporânea.

Os vídeos foram desenvolvidos a partir da leitura do livro Capitães da Areia, de Jorge Amado. Selecionamos trechos em que ocorrem atitudes machistas por parte dos personagens masculinos, como exemplo, a personagem Dora, retratada em vários capítulos da obra de Amado (2008) como objeto sexual masculino. A partir desses trechos, buscamos discutir e debater em sala de aula como a mulher foi discursivizada no decorrer da história, como era tratada no início do século passado, época em que se passa o enredo da obra, o que (não) mudou depois de quase um século e qual é o papel que a mulher desempenha na sociedade contemporânea. Fizemos também questionamentos sobre o padrão de beleza imposto às mulheres pela 
mídia e quais sentidos circulam, na sociedade contemporânea, sobre ser mulher branca ou ser mulher negra. No decorrer de nossas aulas, fizemos a leitura de diversas reportagens, visualizamos capas da revista Boa Forma e assistimos a vídeos que abordam esses temas. Com o objetivo de que eles se organizassem, solicitamos, primeiramente, uma produção textual. Embora tenhamos solicitado a produção textual, não traremos recortes da produção escrita elaborada pelos alunos, uma vez que nosso objetivo principal foi analisar os gestos argumentativos e os indícios de autoria na oralidade dos alunos, em sala de aula e no ambiente virtual. Na sequência, solicitamos a elaboração de um vídeo, por meio da orientação do sujeito-professor:

SP - Com base em tudo o que discutimos sobre o tema mulher e sociedade, no século passado e na atualidade, vocês deverão elaborar, individualmente ou em grupos de até quatro alunos, um vídeo de livre interpretação. Vocês poderão utilizar trechos de música, poemas, imagens, raps etc.

Na sequência, trazemos os recortes 03 e 04, composto por duas telas de vídeos elaborados por dois sujeitos-alunos do $9^{\circ}$ ano $\mathrm{A}$.

Recorte 3

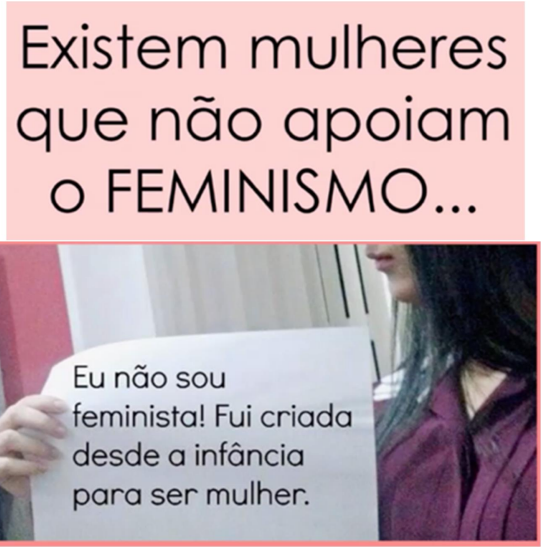

Fonte:

https://www.geledes.org.br/mulherescontra-o-feminismo-lola-aronovich/ Acesso em 24 nov. 2018

\section{Recorte 4}

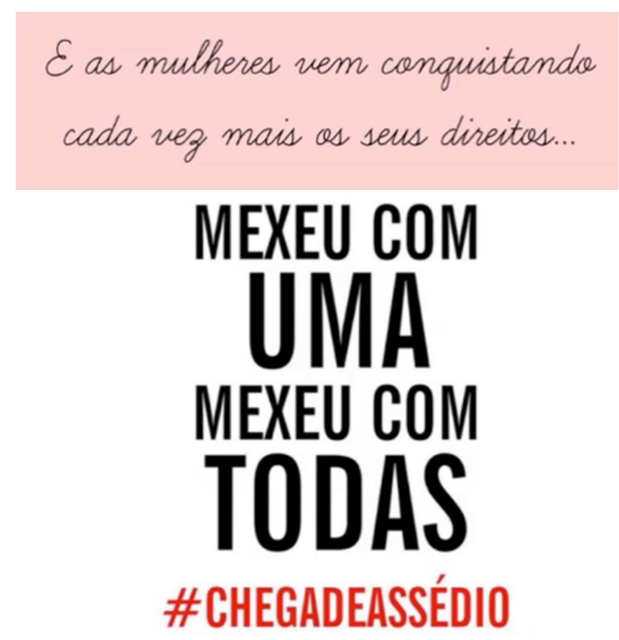

Os sujeitos-alunos iniciaram o vídeo com um texto escrito que aborda a origem do feminismo no Brasil. Na sequência, trazem as imagens acima, as 
quais nos apontam para indícios de que esses sujeitos-alunos utilizaram a imagem do recorte 3 para representar a formação discursiva contrária ao feminismo, que coloca a mulher numa condição de "bela, recatada e do lar", a mulher que se identifica com uma formação discursiva na qual ser mulher é reconhecer como dominante o discurso de que o homem deve ser o chefe da família e, à mulher, cabe cuidar da casa e dos filhos, ou de que há uma diferença de poderes, direitos e saberes entre homens e mulheres que é naturalizada e não deve ser questionada. Portanto, o argumento já está dado. Todavia, como diz Pêcheux (1995), onde há reprodução sempre pode haver resistência. É nesse sentido que estamos entendendo argumentação como uma questão de poder e onde há relação de poder, há resistência; logo, deve haver espaço para argumentação.

Sabemos que todas as relações humanas são permeadas por relações de poder. Para Althusser (1974), a ideologia é todo o sistema que produz valores e ideias considerados naturais na sociedade, apesar de não serem. É o que também ocorre no que diz respeito às relações entre gêneros. Nossa experiência docente nos mostra que ainda é comum nas escolas de educação infantil encontrarmos espaços reservados para meninas coloridos de rosa e com ilustrações de princesas; já os espaços reservados para os meninos coloridos de azul, ilustrados com imagens de super-heróis. Fora da escola, o mesmo acontece nos buffets infantis, com os brinquedos vendidos nas lojas, os jogos na adolescência, o vestuário, os gestos e o palavreado que são ensinados às crianças e aos adolescentes, bem como as relações estabelecidas com os grupos de pares e com as pessoas adultas. Todo esse simbólico vai construindo uma argumentação sobre como é ser homem e mulher na sociedade e levam os sujeitos capturados por essa ideologia a fazer distinção sobre quais atitudes são as mais apropriadas a cada gênero.

Essas atitudes naturalizadas pela sociedade acabam educando meninos e meninas de maneiras distintas, visto que os modelos de homem e de mulher que as crianças e jovens têm à sua volta, na família e na escola, apresentados por pessoas adultas, influenciam a construção de suas referências de gênero e, consequentemente, em atitudes preconceituosas futuras. Podemos 
constatar essas atitudes naturalizadas pela sociedade na declaração ${ }^{5}$ da ministra da Mulher, Família e Direitos Humanos, a pastora Damares Alves, pronunciada no dia 03/01/2019, em cerimônia que marcou o início de sua gestão. De acordo com a ministra, no governo do atual presidente Jair Bolsonaro, "menina será princesa e menino será príncipe 6 ", reforçando na sequência: “Acabou a doutrinação ideológica de crianças e adolescentes". Ainda em vídeo postado por sua equipe, no mesmo dia, a nova ministra declara em meio a aplausos e gritos de apoio: "Menino veste azul e menina veste rosa. Atenção, atenção: é uma nova era no Brasil”.

Considerando que o discurso da atual ministra reverberou pelos meios de comunicação e pelas redes sociais, ficando entre os assuntos mais comentados no dia, reforçando, assim, sentidos já naturalizados por grande parte da sociedade que ainda considera a mulher inferior ao homem, seja no mercado de trabalho ou nas relações de poder, o papel da escola e dos educadores torna-se ainda mais importante, no sentido de não perpetuar a naturalização desses sentidos e construir propostas para a prática da argumentação. Dessa forma, cabe à escola promover a leitura e discussão de temas que envolvem o debate sobre a ideologia dominante de gênero, etnias, padrões de beleza, enfim, sobre o que é legitimado apenas por uma ótica, geralmente perpetuada pela mídia e pelo mercado de consumo. Foi o que tentamos fazer em nosso trabalho: com o objetivo de instaurar um discurso polêmico sobre esse tema, propusemos atividades em que os alunos tiveram acesso ao arquivo, isto é, assistimos a vídeos, fizemos a leitura de reportagens, de capas de revistas femininas e debatemos o capítulo Docas, de Capitães da Areia (AMADO, 2008, p. 83-95), em que a personagem Dora é retratada como objeto sexual masculino e discutimos toda essa questão, possibilitando que os sujeitos-alunos construíssem sentidos a respeito e a despeito da situação da mulher na sociedade.

Diante disso, consideramos que os sujeitos-alunos assumiram a funçãoleitor (PACíFICO, 2012) e puderam argumentar, uma vez que realizaram uma leitura polissêmica em relação ao tema proposto. Constatamos que ao utilizar

\footnotetext{
${ }^{5}$ Disponível em: https://www1.folha.uol.com.br/cotidiano/2018/12/vamos-tratar-meninas-comoprincesas-e-meninos-como-principes-diz-futura-ministra.shtml. Acesso em 12 ago. 2019.

6 Disponível em: https://oglobo.globo.com/sociedade/menina-sera-princesa-menino-principe-dizministra-da-mulher-familia-direitos-humanos-23341446. Acesso em 12 ago. 2019.
} 
a imagem da hashtag "CHEGA DE ASSÉDIO"” e os dizeres "Mexeu com uma mexeu com todas", baseando-se nas leituras e nos gestos de interpretação realizados e fundamentando-se em discursos que passaram a circular na pósmodernidade, os sujeitos posicionaram-se em relação ao objeto discursivo e argumentaram contra a formação discursiva sobre o feminino, a que foi a dominante, durante séculos, como argumentamos acima. Ressaltamos que, nessa formulação, há um deslize de sentido da palavra "mexeu", já que na primeira formulação o termo adquire o sentido de assédio e, na segunda formulação, o sentido de mobilização, o que produz um efeito metafórico, constituindo novos sentidos. Conforme Orlandi (1999, p. 42), "não há sentido sem metáfora. As palavras não têm, nessa perspectiva, um sentido próprio, preso a sua literalidade. É nesse jogo entre paráfrase e polissemia que os sujeitos e os sentidos se movimentam, fazem percursos, (se) significam." Assim, é por meio do deslize de sentido que a formulação cria efeitos de sentido de sororidade, principal alicerce do feminismo. Nesse contexto, os sujeitos-alunos de nossa pesquisa construíram novos sentidos e argumentaram sobre eles para além de uma atividade escolar.

\section{Considerações Finais}

Com o objetivo de instaurar o discurso polêmico (ORLANDI, 2011), garantindo, assim, o direito dos alunos à interpretação, à argumentação e à construção de novos sentidos, procuramos desenvolver nosso trabalho por meio de diversas atividades que incluíssem práticas discursivas argumentativas. Entendemos que, para argumentar, é preciso que a autoria se instale; desse modo, ao possibilitar a instauração do discurso polêmico, presumimos que o sujeito-aluno estaria em condições de argumentar a partir da posição de autor, já que as condições de produção discursivas colaborariam para que isso fosse possível. Nessa perspectiva, convidamo-los à leitura, ao debate, à realização de gestos de interpretação dos sentidos em sua opacidade, ao questionamento de sentidos produzidos pela mídia, à publicização de conteúdos produzidos por eles, ou seja, criamos possibilidades de trabalho diversificadas, empenhando-nos para que as

\footnotetext{
7 Imagem que circulou nas redes sociais e foi compartilhada por várias celebridades, em manifestação motivada pelo suposto assédio sexual envolvendo o ator José Mayer em 2017.
} 
condições de produção em sala de aula e no ambiente virtual possibilitassem que os sujeitos-alunos ocupassem a função-leitor (PACÍFICO, 2012), importante, em nosso entendimento, para a prática da argumentação e da autoria.

Dessa forma, concluímos que os gestos argumentativos e os sentidos produzidos por meio da tecnologia, em ambiente virtual, apontam marcas de autoria dos sujeitos-alunos; no entanto, ao compararmos os discursos realizados em ambiente virtual e na sala de aula, constatamos que foram as condições de produção da leitura e interpretação proporcionadas aos sujeitosalunos, isto é, foram o acesso ao arquivo, a relação dos interlocutores sustentada pelo direito às práticas de argumentação e autoria, a escolha dos livros de literatura realizada pelos sujeitos-alunos e a construção de um site que Ihes possibilitaram o direito à argumentação e não a mudança de espaço discursivo ou de suporte.

\section{Fontes}

TURCI, Valéria Fernandes. Literatuber. Ribeirão Preto, 2018. Disponível em: http://literatuber.com.br/. Acesso em 13 ago. 2019.

\section{Referências}

ALTHUSSER, Louis. Ideologia e aparelhos ideológicos de Estado. São Paulo: Martins Fontes, 1974.

AMADO, Jorge. Capitães da Areia. São Paulo: Companhia das Letras, 2008.

BAUMAN, Zigmund. Modernidade Líquida. Rio de Janeiro: Jorge Zahar Editor, 2001.

CÂNDIDO, Antônio. O direito à literatura. In: Vários escritos. São Paulo: Duas Cidades, 2004, p. 169-191.

DIAS, Cristiane. Análise do discurso digital: sujeito, espaço, memória e arquivo. Campinas: Pontes, 2018.

FOUCAULT, Michel. O que é um autor? In: FOUCAULT, Michel. Ditos e escritos: estética - literatura e pintura, música e cinema. Rio de Janeiro: Forense Universitária, 2001, p. 264-296. 
MOSCA, Lineide do Lago Salvador (org.) Retóricas de ontem e de hoje. São Paulo: Humanitas Editora, 2004.

ORLANDI, Eni Puccinelli. Análise de Discurso: princípios e procedimentos. Campinas: Pontes Editores, 1999.

ORLANDI, Eni Puccinelli. Interpretação: autoria, leitura e efeitos do trabalho simbólico.Petrópolis:Vozes, 1996.

ORLANDI, Eni Puccinelli. A linguagem e seu funcionamento. As formas do discurso. 6. ed. Campinas: Pontes Editores, 2011.

PACÍFICO, Soraya Maria Romano. Argumentação e autoria nas redações de universitários: discurso e silêncio. Curitiba: Appris, 2012.

PACÍFICO, Soraya Maria Romano. O direito à argumentação no contexto escolar. In: PIRIS, Eduardo Lopes; OLÍMPIO-FERREIRA, Moisés (org.). Discurso e Argumentação em múltiplos enfoques. São Paulo: Contexto, 2016, p. 191-212.

PÊCHEUX, Michel. Semântica e discurso: uma crítica à afirmação do óbvio. (Tradução: Eni Orlandi et ali) Campinas: Ed.Unicamp, 1995.

PÊCHEUX, Michel.; FUCHS, C. A propósito da análise automática do discurso: atualização e perspectivas (1975). In: Gadet, Françoise.; Hak, Tony. (Orgs.) Por uma análise automática do discurso: uma introdução à obra de Michel Pêcheux. Campinas: Ed.Unicamp, 2010, p. 159-250.

PFEIFFER, Claudia Regina Castellanos. Que autor é este? 1995. Dissertação (Mestrado) Universidade Estadual de Campinas, Campinas, 1995.

PIRIS, Eduardo Lopes. A Argumentação numa perspectiva materialista do discurso. Linha D'Água (Online), São Paulo, v. 29, n. 2, p. 97-121, dez. 2016. Disponível em: http://www.revistas.usp.br/linhadagua/article/view/120008 Acesso em 13 ago. 2019

POSSENTI, Sírio. Questões para analistas de discurso. São Paulo: Parábola, 2009.

RODRIGUES, Alessandra. Escrita e autoria: entre histórias, memórias e descobertas. Campinas: Mercado das Letras, 2011.

\section{Forma de citação sugerida}

TURCI, Valéria Fernandes; PACÍFICO, Soraya Maria Romano. Argumentação e autoria de adolescentes booktubers: interfaces entre a sala de aula e o ambiente virtual. EID\&A - Revista Eletrônica de Estudos Integrados em Discurso e Argumentação, Ilhéus, n. 19, p. 121-139, ago.2019. DOI dx.doi.org/10.17648/eidea-19-2319. 